\title{
Social Representations and Anthropo-Cultural Aspects of Mental Health in French Polynesia in the Survey "Mental Health in the General Population: Images and Realities".
}

Stéphane AMADEO ( $\nabla$ stephane.amadeo@cht.pf )

CHPF https://orcid.org/0000-0001-7820-6680

Imane BENRADIA

CCOMS Lille

Germaine DAVID

SOS Suicide

Moerani REREAO

SOS Suicide

Annie TUHEIAVA

SOS Suicide

Patrick FAVRO

Universite de la Polynesie Francaise

Steve VILHEM

Etablissements Hospitaliers Vaudois

\section{Aminata SY}

cCOMS Lille

Alban FENNI

SOS Suicide

Ngoc Lam NGUYEN

Centre Hospitalier de la Polynesie francaise

\section{Benjamin GOODFELLOW}

Centre Hospitalier Territorial de Nouvelle-Caledonie

Simone GRAND

Anthropologist

Erick GOKALSING

INSERM U1018

Michel SPODENKIEWICZ

INSERM U1018

Louis JEHEL

INSERM U1018 


\section{Jean-Luc ROELANDT}

cCOMS Lille

Research article

Keywords: social representations, epidemiology, French Polynesia, culture

Posted Date: September 10th, 2020

DOI: https://doi.org/10.21203/rs.3.rs-68823/v1

License: (c) (1) This work is licensed under a Creative Commons Attribution 4.0 International License. Read Full License 


\section{Social representations and anthropo-cultural aspects of mental health in French Polynesia in the survey}

\section{"Mental health in the general population: Images and Realities".}

Stéphane Amadéo 1, 2, 3, 4 , Imane Benradia ${ }^{5,6}$, Germaine David-Vanquin², Moerani Rereao ${ }^{1,2}$, Annie MeunierTuheaiva $^{2}$, Patrick Favro ${ }^{2,}{ }^{7}$, Steve Vilhem ${ }^{8}$, Amanita Sy ${ }^{5}$, Alban Fenni ${ }^{1}$, Ngoc Lam Nguyen ${ }^{1,}{ }^{9}$, Benjamin Goodfellow $^{10}$, Simone Grand ${ }^{11}$, Erick Gokalsing ${ }^{3,12}$, Michel Spodenkiewicz ${ }^{3,13}$,Louis Jehel ${ }^{3}$, 14, Jean-Luc Roelandt ${ }^{5,6}$

1. Hospital Centre of French Polynesia (CHPF), Tahiti, French Polynesia.

2. Suicide Prevention Centre and Association SOS Suicide, Tahiti, French Polynesia.

3. MOODS Team Inserm Unity U1018, CESP, Paris, France.

4. House of Man Sciences - Pacific (MSH-P, UPF), Tahiti, French Polynesia.

5. WHO Collaborative Center - EPSM LILLE Métropole, Lille, France.

6. Inserm Unity UMR 1123 - ECEVE, Paris, France.

7. University of the French Polynesia (UPF), Tahiti, French Polynesia.

8. University Psychiatric Service of Child and Adolescent (SUPEA), Vaudois University Hospital Centre (CHUV), Lausanne, Suisse.

9. Public Health Direction, Tahiti, French Polynesia.

10. Specialized Hospital Centre (CHS), Nouméa, New Caledonia.

11. PhD in biology and anthropology, Tahiti, French Polynesia.

12. CUMP / VigilanS Indian Ocean, Public Mental Health Hospital, La Réunion, France.

13. Mental Health Pole, CIC-EC 1410, University Hospital Centre (CHU) of la Réunion, Saint-Pierre, France

14. University Hospital Centre (CHU) of Fort de France, Martinique, FWI, France.

\section{Corresponding author:}

Dr Stéphane Amadéo

Hospital Centre of French Polynesia, BP 1640. 98 713. Papeete. Tahiti - French Polynesia. Email: stephane.amadeo@cht.pf. Telephone: +689404847 35. Fax: + 68940484725 


\begin{abstract}
Purpose: Better know social representations and socio-cultural aspects of mental illness (FP) is critical to reduce stigma and improve care and prevention of psychiatric illness.

Methods: The Mental Health in General Population Survey (MHGP) was carried out in French Polynesia (FP) in 2015 and 2017, with questionnaires on social representations of the "insane", the "mentally ill", the "depressive" and the various types of help and care. The representative sample of 968 people was built using the quota method. The data were collected in public spaces, anonymously.

Results: The origin of mental health problems is considered mainly as physical, organic or hereditary. Addictive behaviours are the cause of mental illness for $1 / 4$ of respondents. According to the Polynesian population, the "insane" or the "mentally ill" are perceived as excluded, irresponsible, unaware of their conditions and difficult to cure. Depressed people are seen as responsible for their actions, aware of their conditions and who can be treated.
\end{abstract}

Conclusion: The results of this survey show stigmatizing representations of the "insane" and the mentally ill" and significant use of traditional care. They have been incorporated into the mental health plan for FP to improve the care and promotion of mental health.

Key words: social representations, epidemiology, French Polynesia, culture 


\section{Introduction}

Mental health is determined by multiple bio-psycho-social factors. These determinants depend on individuals but on society as a whole, since it influences representations of mental health and conditions the assistance offered to suffering individuals. Improving the treatment and prevention of mental disorders in a given population requires a better knowledge of the anthropo-cultural aspects specific to that population. Historically, a social and scientific approach to behaviours and diseases, particularly in the case of suicide but more generally on the collective representations at work in a given society, began at the end of the 19th century [1]. The social representations of a subject-matter are defined "as knowledge of that subject-matter that can be observed through what people say, how they behave and through any other form of communication". It is transmitted within society through various channels (conversations, institutions, media). This knowledge will then serve as a guideline for interpreting reality [2].

The survey "Mental Health in the General Population: images and realities" (MHGP) was initiated in 1997 in Madagascar after a seminar organized by the WHO and the French Ministry of Cooperation. It is an international multicentre action-research conducted by the Association Septentrionale d'Epidémiologie Psychiatrique (ASEP) and the WHO Collaborating Centre for Research and Training in Mental Health (CCOMS, Lille, France), in collaboration with the Direction de la Recherche, des Etudes, de l'Evaluation et des Statistiques (DREES). Its main objectives are, on the one hand, to describe the representations related to "mental illness", "insanity", "depression" and the different types of help and care, and, on the other hand, to assess the prevalence of the main mental disorders in the general population. The aim is also to make society at large (especially health services, associations and politicians) more aware of the importance of mental health problems and to promote the integration of psychiatry in the community [3]. A national sample was subsequently constituted [4]. The survey was also conducted in Algeria, Belgium, Comoros, Greece, Madagascar, Mauritius, Mauritania, Tunisia, Italy, Spain, Morocco, Seychelles, Tonga and Andorra. To date, the survey is in its third phase of implementation. On the 92 sites that carried out the survey, nearly 78,000 people were interviewed: 64,500 in France, including 3,400 in the French Overseas Departments and Territories and 13,500 for international sites.

In French Polynesia (FP), suicide (1st cause of mortality among young people and high prevalence of suicide attempts) motivated the MHGP survey. Risk and protective factors, socio-anthropological aspects, and the management and prevention of suicide in PF had been the subject of a many research and conferences under the aegis of the WHO (Amadéo, 2014). PF is a group of more than 100 islands in the South Pacific Ocean. 
According to archaeological studies, it was populated at the end of the first millennium AD. Archaeological, linguistic and genetic data locate the remote origin of its population in South-East Asia, and the groups that populate present-day FP came from Samoa and the other islands of Western Polynesia. From there, part of this population went north, east and west to reach the three corners of the "Polynesian triangle", Hawaii, Easter Island and New Zealand [5]. The first European contact was established in 1595 by the Spanish (Mendaña) in the Marquesas and in 1767 by the English (Wallis) in Tahiti. The archipelago officially became French in 1880. It is now an autonomous French Overseas Country of 275,000 inhabitants, with a heterogeneous population composed mostly of Polynesians, Europeans, Chinese and Demis (mixed race). In FP, the survey was coordinated by the association SOS Suicide, with an initial plan to include the South Pacific Region - the purpose being to build regional cooperation in the field of mental health and to compare the results between different Polynesian populations - thanks to the support of the Pacific Fund. The first phase (training of the investigators and the beginning of the field survey) was thus carried out in the presence of observers from Tonga and New Zealand. The survey was then conducted in Tonga in November 2017 and is still being prepared for New Zealand and Australia.

Through the social representations associated with these 3 concepts, the "insane", the "mentally ill" and the "depressive" in the Polynesian population, specific behaviours will be analysed such as dangerousness, exclusion, the representation of the origin of the disorders and calling upon health care, in particular the traditional type, by the population.

\section{Methods}

\section{Population}

The sample, which was as representative as possible of the population living in the geographical area concerned, was constituted on the basis of the latest census data adjusted for the period of the survey (FP Institute of Statistics, 2014) by respecting socio-demographic quotas (sex, age, level of education, socioprofessional category). The data were collected anonymously from randomly solicited persons in public places (town halls, streets, shops, etc.) with the exception of medical centres, by 30 trained interviewers (nursing and psychology students), using questionnaires administered during face-to-face interviews under the supervision of clinicians. The questions explored the interviewees' own representations as well as the presence of current or 
past mental disorders and the therapeutic assistance they resorted to. The methodology of the survey was previously described [4], as well as the main results in France [6-7], [8-9] and internationally [10].

The sample consisted of 968 persons aged 18 years and over from the population of four main islands of PF (total population: 153,408). The study was conducted between October and November 2015 on the islands of Tahiti and Moorea, and February 2017 on the islands of Huahine and Bora Bora.

\section{Questionnaires}

The interview began with an overview of the objectives and methods of the study in which respondents were informed that they would remain anonymous and informed consent was obtained. They were then asked a series of 50 open-ended questions in the first socio-anthropological section of the survey questionnaire: three openended questions for qualitative analysis ("According to you, what is an insane person? A mentally ill person? A depressive person?"); eighteen questions describing behaviours and twenty-nine questions exploring social representations of healing, awareness of the trouble, responsibility, suffering, social exclusion and psychiatric care). The construction of this questionnaire was the subject of a preliminary survey. The data collected during the interviews were analysed by a committee of experts. In the second section, psychiatric diagnoses of people were assessed using the MINI (Mini International Neuropsychiatric Interview) [11]. This last section is the subject of another publication [12].

At the end of the 30-60 minute interview, questions on specific cultural aspects of FP was submitted to all subjects in a complementary questionnaire developed by FP clinicians and anthropologists.

This article will focus on the results of the first section of the survey assessing social representations and help-seeking behaviours among subjects who presented a mental disorder or their relatives and the specific questions on FP. The data collected during the interviews were analysed by a committee of experts including a panel of three psychiatrists and four psychologists for validation purposes.

The survey was approved by the FP Ethics Committee (CEPF, Opinion No. 55, 24 May 2012).

\section{Data analysis}

The data were entered using the Epi-info software and analysed with the open source R software version 3.5.1 with chi 2 independence test and Fischer test in case of theoretical number of staff $<5$ (R Core Team R: http://www.R-project.org). 


\section{Results}

The composition of the sample (Table 1) reflects the census of FP with minor differences such as slightly more women compared to men in our sample (50.6\%), unlike in the census (49\%). Similarly, slightly more people with jobs (47.9\% in the sample versus $44 \%$ in the census), a lower rate than in France (63\%). Certain differences in educational levels can influence social representations. In FP, there is a higher rate of subjects with both no diploma and who have not finished primary school (28.4\%) compared to the national sample $(5 \%)$

\section{Representations of respondents about "insanity", "mental illness" and "depression"}

Perceptions of the "insane" and the "mentally ill" close to each other and associated with dangerousness and abnormality.

Some behaviours are frequently associated (in two thirds of cases) by the respondents with "insanity" or "mental illness" such as "committing rape, incest or murder", "delirium or hallucinations" or "being violent towards others (wife/husband, children, others) or towards oneself". Nearly nine out of ten people consider these same behaviours "abnormal" and "dangerous", except for "delirious, hallucinating", where six out of ten people associate it with dangerousness. Similarly, "making a suicide attempt", "crying often or being sad" and "being isolated and trying to be alone" are behaviours that are mostly associated by the Polynesians surveyed with the notion of "depression". Finally, "having a nervous breakdown or convulsions", "drinking alcohol regularly" or "using drugs", being "neglected" or "anxious" are not associated with "insanity", "mental illness" or "depression". Alcohol and drug addictive behaviours are considered as "dangerous" by respondents.

The "insane" person is most recognizable by his or her behaviour and the "depressive" person by his or her appearance

The Polynesian population has a different perception of the "insane", the "mentally ill" and the "depressive". Two thirds of people declare that one could recognize an "insane person" by his behaviour, and one third by his words. The "depressive" could be recognized by his or her appearance or behaviour for nearly $42 \%$ of respondents. Finally, recognizing the "mentally ill" is associated with his behaviour (48\%) and then with his words $(35 \%)$. 
Mainly physical or addictive causes for "mental illness" and more diverse causes for "depression" (Graph 1)

Respondents have a very different idea of what could cause "insanity", "mental illness" and "depression". For almost $40 \%$ of them, the cause of "mental illness" would lie in a physical problem, be it a deficit, an organic, hereditary or genetic disorder. Addictive behaviours are said to be the cause of "mental illness" for a quarter of the people surveyed. As for "insanity" and "depression" these are causes linked to significant events. For the people surveyed, it is often life events $(23 \%)$, such as bereavement, physical assault, or challenging love relationships (19\%), that can make a person "insane". "Depression" is mainly due to problems in love relationships $(33 \%)$, a life event $(25 \%)$ or relationship difficulties in general $(22 \%)$. Workrelated problems are cited by almost one person in five as a possible cause of "depression", which is almost absent as a cause given for "insanity" and "mental illness".

According to the population: the "insane" and the "mentally ill" are perceived as excluded, irresponsible, unaware of their conditions and difficult to cure, whereas the "depressive" are perceived as responsible for their actions, aware of their conditions and who can be cured

The Polynesian population clearly expresses (more than 90\%) the difference in the perception of the severity of the disorders between the "insane" and the "mentally ill" on the one hand, and the "depressive" on the other. The perception of the social future of those it considers as "insane" and "mentally ill" is very negative.

\section{Representations of looking for health care}

Representations of health care: medication is the most frequently mentioned treatment (Graph 2)

For the "insane" and the "mentally ill", drug treatment and hospitalisation are the most frequently mentioned remedies (30 to $40 \%$ ), while for the "depressive" it is emotional support and psychotherapy (28 to $42 \%)$

More specialized care for the "insane" and the "mentally ill"

Psychiatric professionals are the main recourse recommended for a relative designated as "insane" or "mentally ill" (around 65\%), whereas for the "depressed" relative, even if the use of psychiatric professionals is significant (more than 50\%), the difference is particularly clear for the use of emotional (18\%) or religious (5\%) 
help. Consulting general practitioners is almost identical than other recourses $(30 \%)$ and the very low use of magical-religious and traditional practitioners (almost nil).

\section{The first declared source of help: family and friends}

If the people were suffering from mental illness themselves, they said that they would first seek help from family and friends (52\%), a psychiatric professional $(16.7 \%)$ or a general practitioner $(13.5 \%)$. Far behind is turning to religious $(6.8 \%)$ and even less to magical-religious people $(0.4 \%)$. A relatively significant number of subjects do not seek any kind of outside help (6.8\%).

\section{Finding actual help for persons identified with a mental disorder}

For all subjects with disorders identified in the MINI, looking for social support is reported to be more frequent, particularly for depressive and anxiety disorders (clearly over 50\%), followed by health professionals (around 20\%) and religious people (15\%). Turning to psychiatric professionals is almost nil for depressive patients, while it is highest among subjects suffering from psychotic disorders (15.8\%), almost as frequent as looking for social support in this case.

In the complementary questions, turning to traditional care appears to be more frequent $(22.21 \%)$ than in the questionnaires on representations with respectively Tahitian medicines (19.6\%), massages (14.6\%) and healers $(3.6 \%)$.

The presence of a disorder identified with the MINI is not related to turning more to traditional care, except for the psychotic related disorder $(\mathrm{p}<0.05)$ (Table 2$)$. There was a high frequency of psychotic symptoms in the Polynesian population according to the MINI questionnaire, a part of which could be more related to cultural beliefs than to pathology $(18.4 \%$ ideas of persecution, $95 \%$ CI $[16.03-21.01] ; 13.6 \%$ visual hallucinations [11.57-16]; 10.3\% auditory hallucinations [8.52-12.46]).

On the other hand, the participants who declared a Polynesian cultural identity and people of mixed race were significantly more likely $(\mathrm{p}<0.01)$ to report using traditional Polynesian treatments (Table 3).

\section{Discussion}

Representation of the "insane", the "mentally ill" and the "depressive

Comparing our results with those of the other MHGP survey sites [13], we find, as in previous studies, 
that the distinction between "insane/mentally ill" and "depressive" is strong, both in metropolitan France and in overseas France $[8,14]$. The representations of the "insane" and the "mentally ill" are those of a person who is dangerous, unpredictable, incurable and therefore often excluded; those of the "depressive" are more acceptable, non-dangerous (except for suicide attempts) and curable: "The disturbances affecting the state of mind and "being" are everywhere identified as specific to the "depressive" as compared to the "insane" and the "mentally ill", whose disturbances manifest themselves essentially at the level of the motor sphere and at the level of "acting"" [15]. In this perspective, the basis of the representations of the "insane", the "mentally ill" and the "depressive" is not different from other countries in the world explored by the MHPG survey. Indeed, in most studies on social representations in the world, subjects with mental disorders are described as "dangerous, unpredictable, and poorly responsive to treatment" [16], or are carriers of "notions of danger and threat that are said to be responsible for the genesis of feelings of fear, mistrust and antipathy, and which thus form the basis of attitudes of exclusion and rejection" [17]. Depression, on the other hand, is better accepted and integrated.

\section{Representations of the origins of mental disorders: Of insanity in Tahitian}

The predominance of the physical origin of mental disorders in the survey contrasts with the traditional conception of diseases among Polynesians. Indeed, this traditional magical-religious representation is very low $(0.5 \%)$ in all three categories. From a historical point of view, this representation has evolved from the first contacts with Europeans through phases of abandonment and then renewal [18].

In Oceanian thought, there is no separation between nature and culture. In order to correspond to European concepts, words were invented with varying degrees of accuracy. The traditional terminology of mental disorders requires further insight from anthropologists. $M a^{\prime} a m a^{\prime} a$ is madness but also stupidity or debility (ma'āu). Ma'ama'a tāne, ma'ama'a vahine corresponds to the madness of love for a man or a woman that can lead to suicide ('ōnohi) or murder (taparahi ha'apohe), so great is the suffering (mäuiui), the grief (hevaheva) of separation (ta'a 'êra'a) to the point that he or she loses ('ua mo'e) common sense (te hìro'a). But common sense can also be lost $\left(m o^{\prime} e\right)$ under the influence of anger (riri), when it becomes rage (hae) where one loses one's humanity and becomes bestial.

Tiurai, the famous Polynesian healer, distinguished four types of diseases (1917): diseases of the body, tino; of the mind, mana'o; of the spirit of the living, vārua; and of the spirit of the deceased, vāite. Of course, the diseases of the body could not only be bodily, but they could also testify to a sick mind after a fright, ri'ari'a, a trauma, fati. The body can also testify to an illness of the spirit of the living during a mourning or a separation. 
Taravana is the drunkenness of the depths which can lead the diver to Tapatari which is death by diving or bring back a being who is rambling, irresponsible, totally different from the one he was. By extension, also means all kinds of loss of common sense.

The linguistic context of $\mathrm{Pf}$ is rich: there are many words that designate in a very imaginative way the moods and states of mind. This richness is expressed in the Tahitian language (reo mä'ohi), mentioned above and used in everyday language, listed by linguists [19], or less commonly used, such as aoaoa (vagabond, fool, delirious), listed by the Tahitian Academy [20], but also in other Polynesian languages (Marquesan, pa'uomotu, rapa, mangarévien, for instance...). In the Marquesan language, for example, there is a multitude of expressions that will characterize emotions, which can reach a state close to depression: "Te koekoe ue translates as the sorrow we feel when our relatives or friends die, when we are seriously ill or when we are confronted with great difficulties. Te koekoe ue literally means bowels in pain, bowels in tears" [21].

However, there is no specific term for "depressive" that corresponds to the Western sense of illness. The closest term would be fiu. This word can have several meanings: nonchalance, detachment caused by states of mind. It expresses not only this feeling of weariness, disgust, boredom but also languor, rejection, the desire to quit everything, lack of will and strength and drive, the feeling of being fed-up it generates. According to the analysis of a Polynesian anthropologist (Edgar Tetahiotupa, personal communication), fiu has an equivalent in the Tuamotu language (reo pa'umotu) which is hiu. This term shares the same meaning as another word, hakumani, which means: weary, having enough, tired. Fiu would be more a defence mechanism against depression than depression itself: "it acts as a safety valve. Intrinsically free of moral and/or religious contingencies that are too oppressive ... fiu becomes salutary by preventing the person from sinking into depression".

In a thesis on psychology, a metropolitan psychiatrist practising in Tahiti [22] used questionnaires addressed to his patients to question the different meanings of the word: "big" fiu would be closer to depression, or even melancholy. According to this author, depression may pass unnoticed as a disorder because it is a typical state of mind, a very common Polynesian mood, whereas the major form of fiu could correspond to a depressive state in the bipolar spectrum. The medical thesis of another psychiatrist, who also practiced in Polynesia [23], is along these lines.

There is a certain discrepancy between clinical practice and the answers given in the questionnaire of the representations of this survey, where the magico-religious origins attributed to the disorders seem to be minimized, as we will see later in the way people resort to mental health care. The difficulty may also come from 
the fact that several representations of the disease coexist in a same person. It can be seen that here as elsewhere there is a crossbreeding of representations in the world, as medical anthropology has predicted [24].

The context of the survey thus perhaps did not allow, in spite of methodological precautions (anonymity, confidentiality), the expression of the traditional Polynesian representation. Responses may be more sensitive to the social desirability bias associated with the interviewer, a health professional. This effect has been discussed for mixed sites such as Guadeloupe [25]. In this hypothesis, cultural and ethnic mixing may not be objectively reflected. This response bias has led to under-reporting of traditional representations in other sites.

In the other survey sites, the causes attributed by the populations interviewed to "insanity" differed according to the countries studied: in Madagascar, magical-religious origin prevailed [26], in Reunion Island, drug or alcohol consumption was mentioned above all (the "zamaliens", cannabis users and the "rak drinkers", alcoholics) in Tunisia, insanity was perceived as having a relational origin [15], in Guadeloupe, love relationships was in the forefront [25], whereas for the French it was seen as secondary to life events [9]. Concerning "mental illness", the physical causes were predominant. The origins of "insanity" and "mental illness" are classically linked to the supernatural or magical-religious in societies that are still traditional [27] with a projection of the origin of the disorders onto the other, whereas they are considered more individual or an internal reaction to life events or to the stress of work in more industrialized societies [28].

\section{Representation in relation to exclusion}

In our survey, the "insane" appeared stigmatized, rejected and perceived as excluded at the family, social and professional levels, the "mentally ill" was slightly less excluded and the "depressive", unlike the others, better integrated into society. According to the comparison with the results of the other sites, Polynesian families were more tolerant than Western families, as were Maghrebi families [15] and Malagasy families [26]. However, this tolerance of families in FP has its limits. This was also highlighted by our survey in Mauritania, and in Algeria [29] where the exclusion was mainly within the family itself.

\section{Representations of health care and use of traditional health care}

As a first step, in the hypothesis of a psychological difficulty, turning to the magical-religious and the religious is very low in the questionnaires on representations. "Depression" was not recognized as a genuine disease, but rather as a reactive and brutal, but temporary and transitory state of mind. Here the notion of moral 
pain that "shames" or which is not expressed because of a greater tolerance of pain in general comes into play. This makes it difficult to accept drug treatment for this condition and to seek the help of psychiatrists.

The reported use of traditional Polynesian medicines is higher in the complementary questions. The choice to directly ask about the use of traditional medicines, body care or healers with the corresponding Polynesian terms, may have helped to better reflect the importance of traditional medicine among Polynesians. Moreover, this use is mostly reported by people who identify themselves as Polynesian or of mixed race. This result is consistent with our clinical practice. A large proportion of patients still use either traditional healers (tahu'a), monoi oil massage (taurumi) or herbal medicines (raau tahiti), like in la Réunion (use of zerbaz).

The still very significant use of traditional therapies is found in an ethno-psychiatric study carried out in the "Polynesian triangle" [30]. More recently, meetings between traditional practitioners and healthcare personnel from the FP Hospital Centre have begun to work together to provide care that takes better account of culture [31]. In this same integrative current of complementary medicine between traditional and modern care, a clinical trial of a suicide prevention device with an alliance between traditional care (monoi massage) and psychiatric and psychological care has provided promising results in reducing the frequency of suicidal acts [32]. These approaches are recommended at the international level [33] in order to develop integrative medicine.

\section{Conclusion}

This survey, the first of its kind in FP, highlights the stigmatization of the "insane" and the "mentally ill", with the related notions of dangerousness, incurability and organicity (for the mentally ill only), which reinforce exclusion and make health care difficult for these patients. The situation of the "depressive" is better accepted, but also trivialized; looking for help in case of depression can be slowed down by the denial of a disorder which can sometimes have critical consequences, and where suicidal risk may be minimized.

On the other hand, despite the low use of traditional and magical-religious care indicated in the survey on representations, a more important place for this type of care is to be found in the specific questions and in clinical experience. Doctors, most of them European, have initiated collaborative work with traditional practitioners for the treatment of organic pathologies or the prevention of suicidal behaviour.

The data from the MHGP survey needs to be further developed but has already been included in the mental health plan of FP. Since the majority of people with a mental disorder are at home and not in hospital, this plan provides better care within the community. This possibility is very well accepted by the Polynesian 
population, witness the mostly positive answers to the question, "Would you accept to take back home, if followed or treated, someone who is "insane", "mentally ill" or "depressive"?). In this sense, the psychiatric teams in hospitals and clinics will be led to work with the communities, and therefore will need to know as much as possible about their beliefs and ways to look for help. The usual access to general medicine in Tahiti is very low compared to other countries, and the primary health care system is not the first resort. A more anthropocultural approach can promote integrative medicine. This is undoubtedly an avenue to be developed in practices more adapted to the Polynesian culture, for example by integrating therapeutic approaches and recovery training (including therapeutic education for patients). They would only be efficient (in the sense of care - comprehensive care and not only of the disease) if the interested persons, patients and traditional practitioners are integrated with the more official professionals. This approach will allow for mutual understanding, in order to strengthen the alliance in care and harmonize the representations of all people concerned.

\section{Conflict of Interest}

None

\section{Acknowledgements and Contributors}

This action-research is carried out by the Association Septentrionale d'Epidémiologie Psychiatrique (ASEP), the World Health Organization Collaborating Centre for Research and Training in Mental Health (CCOMS, EPSM Lille Métropole, Lille - France) and in French Polynesia the association SOS Suicide. We would like to thank the Pacific Fund (France Ministry of Foreign Affairs), the Ministry of Health of French Polynesia, the Social Welfare Fund (CPS), the FP Hospital Centre and Health Department, Air Tahiti Nui, municipalities of Tahiti, Moorea, Huahine and Bora Bora, the IFPS (Institut de Formation des Professions de Santé) and the ISEPP (l'Institut Supérieur de l'Enseignement Privé), Eric Conte, Edgar Tetahiotupa and Monique Bonnefoy for their contribution to the rereading the manuscript. 


\section{References}

1 Durkheim E. (1967). Représentations individuelles et représentations collectives. In: Sociologie et philosophie, Collection « Le sociologue », Paris. Editions PUF. Jodelet D. (2003). « Représentations sociales de la maladie mentale et insertion des malades mentaux », in: Jean-Claude Abric éd., Exclusion sociale, insertion et prévention. Toulouse, ERES, «Hors collection », 97-113, DOI: 10.3917/eres.abric.2003.02.0097. URL: https://www.cairn.info/exclusionsociale-insertion-et-prevention--9782865864423-page-97.htm

Roelandt JL, Caria A, Mondiere G. (2000). La santé mentale en population générale : images et réalités. Présentation générale de l'enquête. L'Information Psychiatrique, 76 (3), 279-292. Caria A, Roelandt JL, Bellamy V, Vandeborre A. (2010). « Santé Mentale en Population Générale : images et réalités (SMPG) » : Présentation de la méthodologie d’enquête. L’Encéphale, 36,1-6. Conte, E. (2019). L'origine des Polynésiens et le peuplement du Pacifique insulaire in: Conte, E. (Ed) Une histoire de Tahiti des origines à nos jours.. Au vent des îles Ed., Tahiti, pp. 9-32. Bellamy V, Roelandt JL et Caria A. (2004). Troubles mentaux et représentations de la santé mentale premiers résultats de l'enquête Santé mentale en population générale. Etudes et Résultats oct, 347, 1-12. Bellamy V, Roelandt JL et Caria A. (2005). Premiers résultats de l'enquête Santé Mentale en Population Générale : images et réalités. L’Information Psychiatrique, 81(4), 295 -304. Roelandt JL, Caria A, Anguis M, Benoist J, Bryden B, Defromont L. (2003). La santé mentale en population générale: images et réalités. Résultats de la première phase d'enquête 1998-2000., L'Information psychiatrique, 79, 867-78 mental » et du « dépressif» en population générale en France. In : Giordana JY (dir.), La stigmatisation en psychiatrie et en santé mentale. Paris, Masson.

10 Chabaud F, Benradia I, Bouet R, Caria A, Roelandt JL. (2017). Sociodemographic and mental health risk factors: Global and local conditions according to the Survey results "mental health in the general population" in 18 international locations. Encephale. Dec;43(6):540-557. doi: 10.1016/j.encep.2016.04.009. Epub 2016 Sep 20.

11 Sheehan DV, Lecrubier Y, Sheehan KH, Amorim P, Janavs J, Weiller E, Hergueta T, Baker R, Dunbar GC. (1998). The Mini-International Neuropsychiatric Interview (M.I.N.I.): the development and 
validation of a structured diagnostic psychiatric interview for DSM-IV and ICD-10, J Clin Psychiatry, 59 Suppl 20, 22-33. Amadéo S, Benradia I, Sy A, Rereao M, David-Vanquin G, Favro P., Meunier-Tuheaiva A., Fenni A., Nguyen NL., Goodfellow B., Jehel L, Roelandt JL. (submitted). French Polynesia suicidal risk results of the international survey « Mental Health in General Population: Images and Realities" Roelandt J-L, Caria A, Defromont L, Vandeborremerie N. (2010). Les représentations du « fou », du « malade mental » et du « dépressif » en population générale en France. L’Encéphale, 36(3 Suppl),7-13.

14 Goodfellow B, Defromont L, Calandreau F, Roelandt JL. Images of the 'Insane', the 'Mentally ill' and the 'Depressed' in Nouméa, New Caledonia. (2010) International Journal of mental health, 39 (1), 82 98.

15 Cherif W, Elloumi H, Ateb A, Nacef F, Cheour M, Roelandt JL, Caria A. (2012). Représentations sociales de la santé mentale en Tunisie. La Tunisie Médicale, Vol 90 ( n011 ), 793 - 797.

16 Hayward P, Bright JA. (1997) Stigma and mental illness: a review and critique. J of mental health; 6: $345-54$.

17 Quintin P, Klein P, Carriere P. et al. (2001). L’image de la schizophrénie et des schizophrènes auprès du grand public Nervure, 14: 16-19.

18 Gleizal V. (2019). La fin de la souveraineté tahitienne et l'apprentissage de la colonisation, in: Conte, E. (Ed) Une histoire de Tahiti des origines à nos jours. Au vent des îles Ed., Tahiti.

19 Lemaitre Y. (1995). Lexique du tahitien contemporain. Éditions de I'Orstom-IRD. Institut français de Recherche scientifique pour le Développement en coopération. Paris.

20 Fare Vanaa (Tahitian Academy) (2020). http://www.farevanaa.pf/dictionnaire.php.

21 Tetahiotupa E. (2007). Des mots pour le dire, humeur polynésienne. Psy-Cause, 12.

22 Virieu R. (1981). Un éprouvé psychique polynésien, le Fiu : Approche psychologique clinique et psychopathologique, Thèse de psychologie, Paris.

23 Hureaux J. (1986). Dépression en Polynésie, Thèse médecine. Reims.

24 Benoist J. (2007/2008) « Logiques de la stigmatisation, éthique de la déstigmatisation », L'information psychiatrique, (Volume 83), 649-654. DOI : 10.3917/inpsy.8308.0649. URL : https://www.cairn.info/revue-1-information-psychiatrique-2007-8-page-649.htm 

Guadeloupe : résultats préliminaires de l'étude « La santé mentale en population générale : images et réalités », L’Information Psychiatrique , 76(3), 293-298. Andriantseheno M. (2003). La santé mentale à Madagascar. L’Information psychiatrique, 79, 913-919. Foster GM (1976). Disease etiologies in non-western medical systems, Am. Anthropologist, 78,773-82. Downey KJ. (1967). Public images of mental illness: a factor analytica study of causes and symptoms. Soc. Sci. Med, 1: 45-65. Sider C, Kacha F, Benradia I, Roelandt JL, Mouchenik M. (2015). De la stigmatisation à l'exclusion de la personne désignée comme malade mentale en Algérie. Perspectives Psy , 54 (2), 1-1.

30 Grand S. (2007). Tahu'a, tohunga, kahuna - Le monde polynésien des soins traditionnels. Ed Aux vents des îles, Tahiti.

31 Poanui G. (2019). Un projet polynésien de médecine intégrative. Analyse ethno-médicale de la rencontre entre Tradipraticiens et Professionnels de Santé à Tahiti, Thèse de Médecine. Université Claude Bernard - Lyon 1.

32 Amadéo S, Nguyen NG, Teai T, Favro P, et al. (submitted). Supporting effect of Body Mediation Care with ylang ylang aromatherapy and Mobile Intervention Team in Suicide Prevention: A Pilot study.

33 WHO. (2013). Stratégie de l'OMS pour la médecine traditionnelle pour 2014-2023. Organisation mondiale de

Santé, https://apps.who.int/iris/bitstream/handle/10665/95009/9789242506099_fre.pdf?sequence=1. 
Table 1: Socio-demographic characteristics of the Polynesian population and National

\section{sample.}

\begin{tabular}{|c|c|c|}
\hline $\begin{array}{l}\text { Socio-demographic characteristics and Statistics } \\
\text { (NS: not significant } \quad *: p<0.05 \quad * *: p<0.01 \quad * * *: p<0.0001)\end{array}$ & $\begin{array}{c}\text { Polynesian } \\
\text { Population } \\
(n=968)\end{array}$ & $\begin{array}{l}\text { National Sample } \\
\qquad(\mathrm{n}=889)\end{array}$ \\
\hline \multicolumn{3}{|l|}{ Gender (NS) } \\
\hline Male & $49.4 \%$ & $46.1 \%$ \\
\hline Female & $50.6 \%$ & $53.9 \%$ \\
\hline \multicolumn{3}{|l|}{ Age $(* * *)$} \\
\hline From 18 to 29 & $29 \%$ & $25.5 \%$ \\
\hline From 30 to 39 & $21.3 \%$ & $20.1 \%$ \\
\hline From 40 to 49 & $20.9 \%$ & $14.7 \%$ \\
\hline From 50 to 59 & $14.9 \%$ & $13.6 \%$ \\
\hline 60 and older & $13.9 \%$ & $26 \%$ \\
\hline \multicolumn{3}{|l|}{ Marital Status $(* * *)$} \\
\hline Single & $25.1 \%$ & $27.5 \%$ \\
\hline Married, common-law Marriage, cohabitation, civil union & $64.7 \%$ & $54.5 \%$ \\
\hline Separated, divorced & $5.7 \%$ & $8.4 \%$ \\
\hline Widow(er) & $4.5 \%$ & $9.6 \%$ \\
\hline \multicolumn{3}{|l|}{ Educational level (***) } \\
\hline No school & $2.5 \%$ & $0.8 \%$ \\
\hline Primary school not finished & $25.9 \%$ & $4.2 \%$ \\
\hline Primary school finished & $10.1 \%$ & $18.9 \%$ \\
\hline Secondary school not finished & $29.4 \%$ & $34.2 \%$ \\
\hline Secondary school finished & $17.5 \%$ & $14.5 \%$ \\
\hline University level or equivalent & $14.6 \%$ & $27.4 \%$ \\
\hline \multicolumn{3}{|l|}{ Current work $(*)$} \\
\hline Yes & $47.9 \%$ & $53.5 \%$ \\
\hline No & $52.1 \%$ & $46.5 \%$ \\
\hline \multicolumn{3}{|l|}{ Professional Status $(* * *)$} \\
\hline Retired & $13.6 \%$ & $23.4 \%$ \\
\hline Unemployed & $17.7 \%$ & $6.6 \%$ \\
\hline Student & $6.9 \%$ & $9.7 \%$ \\
\hline Housewife / Househusband & $6.4 \%$ & $3.4 \%$ \\
\hline Without & $7.4 \%$ & $3.4 \%$ \\
\hline \multicolumn{3}{|l|}{ Occupation $(* *)$} \\
\hline Farmer & $1.2 \%$ & $1 \%$ \\
\hline Skilled tradesman, retailer, entrepreneur & $4.9 \%$ & $3.5 \%$ \\
\hline Manager, professional & $5 \%$ & $8.4 \%$ \\
\hline Middle-ranking occupation & $7.9 \%$ & $10.9 \%$ \\
\hline Employee & $17.6 \%$ & $17.2 \%$ \\
\hline Labourer & $11.4 \%$ & $12.5 \%$ \\
\hline \multicolumn{3}{|l|}{ Monthly family income $(* *)$} \\
\hline Less than $100239 \mathrm{XPF}$ & $20.7 \%$ & $15.4 \%$ \\
\hline 100239 to $155131 \mathrm{XPF}$ & $16.5 \%$ & $21.8 \%$ \\
\hline 155131 to 300716 XPF & $27.9 \%$ & $41 \%$ \\
\hline More than 300716 XPF & $34.9 \%$ & $21.8 \%$ \\
\hline \multicolumn{3}{|l|}{ Predominant cultural identity } \\
\hline Polynesian & $75.6 \%$ & \\
\hline European & $11.1 \%$ & \\
\hline Chinese & $1,6 \%$ & \\
\hline Mixed & $9,8 \%$ & \\
\hline Other & $2.0 \%$ & \\
\hline
\end{tabular}


Table 2: Use of traditional treatments in population with disorders

\begin{tabular}{|c|c|c|c|}
\hline \multicolumn{2}{|l|}{ Disorders } & \multirow{2}{*}{$\begin{array}{l}\begin{array}{l}\text { Use of traditional } \\
\text { treatments }\end{array} \\
26,8 \%(n=53)\end{array}$} & \multirow{2}{*}{$\begin{array}{l}p \\
0,807\end{array}$} \\
\hline Mood Disorders & Yes & & \\
\hline & No & $25,9 \%(n=199)$ & \multirow{3}{*}{0,204} \\
\hline \multirow[t]{2}{*}{ Anxious Disorders } & Yes & $23 \%(n=50)$ & \\
\hline & No & $27,1 \%(n=194)$ & \\
\hline \multirow[t]{2}{*}{ Alcohol problems } & Yes & $23,3 \%(n=31)$ & \multirow[t]{2}{*}{0,044} \\
\hline & No & $26,5 \%(n=220)$ & \\
\hline \multirow[t]{2}{*}{ Drug problems } & Yes & $30,6 \%(n=19)$ & \multirow[t]{2}{*}{0,398} \\
\hline & No & $25,8 \%(n=233)$ & \\
\hline \multirow[t]{2}{*}{ Psychotic disorders } & Yes & $41,7 \%(n=15)$ & \multirow[t]{2}{*}{$0,0294 *$} \\
\hline & No & $25,4 \%(n=237)$ & \\
\hline
\end{tabular}

*p $<0.05$ 
Table 3: Use of traditional care according to cultural identity

Use of traditional treatments

\begin{tabular}{|c|c|c|}
\hline Cultural Identity & No & Yes \\
\hline Polynesian & $72.8 \%(n=532)$ & $27.2 \%(n=199)$ \\
\hline European & $86.9 \%(n=93)$ & $13.1 \%(n=14)$ \\
\hline Chinese & $86.7 \%(n=13)$ & $13.3 \%(n=2)$ \\
\hline Mixed & $66.3 \%(n=63)$ & $33.7 \%(n=32)$ \\
\hline Other & $73.7 \%(n=14)$ & $26.3 \%(n=5)$ \\
\hline
\end{tabular}

Exact Fisher's test : $p=0.0055$ 
Graph 1: What do you think can make "insane" / "mentally ill" / "depressed"?

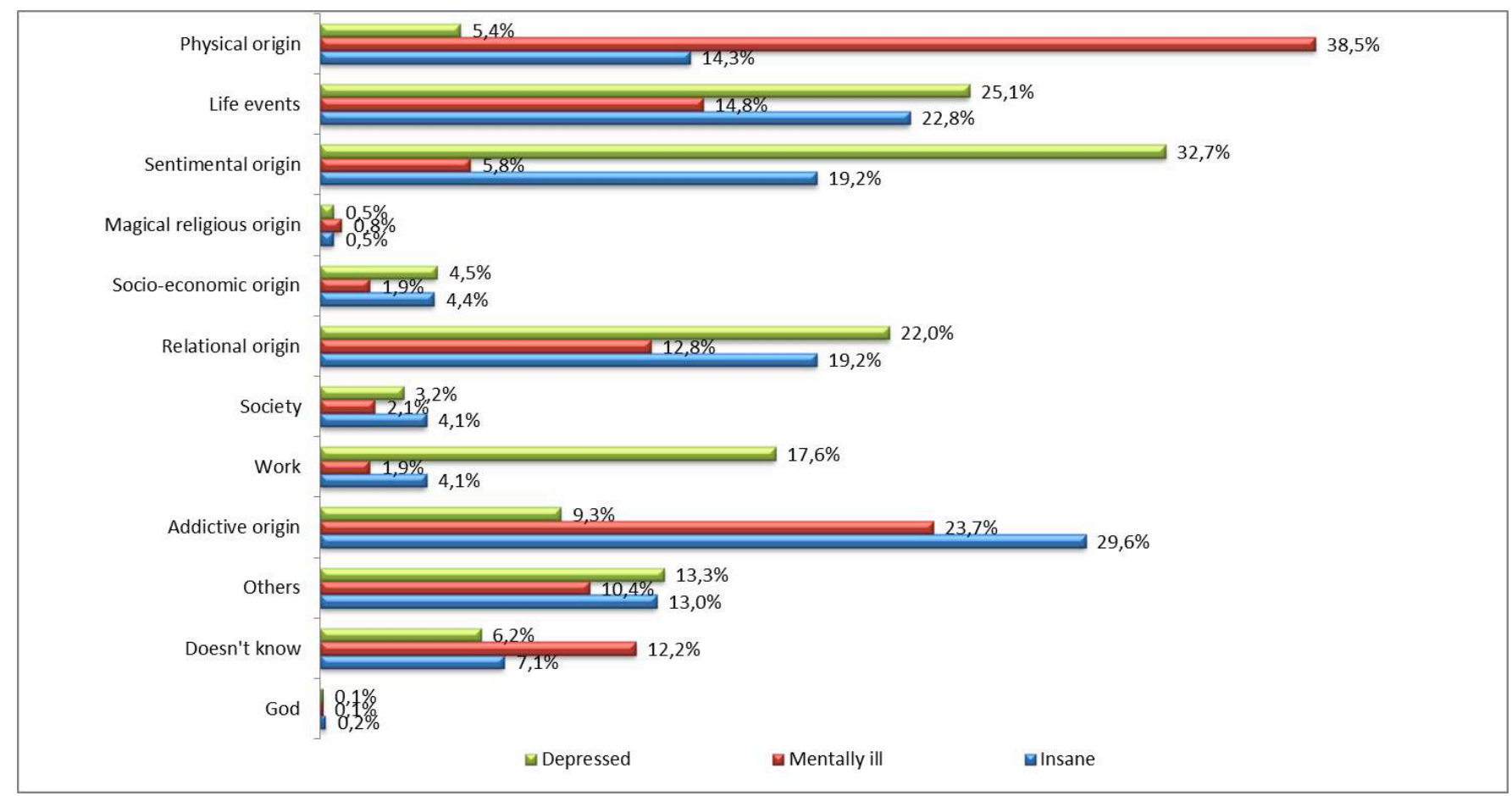


Graph 2: In your opinion, how can we treat an "insane", a "mentally ill", a "depressed"?

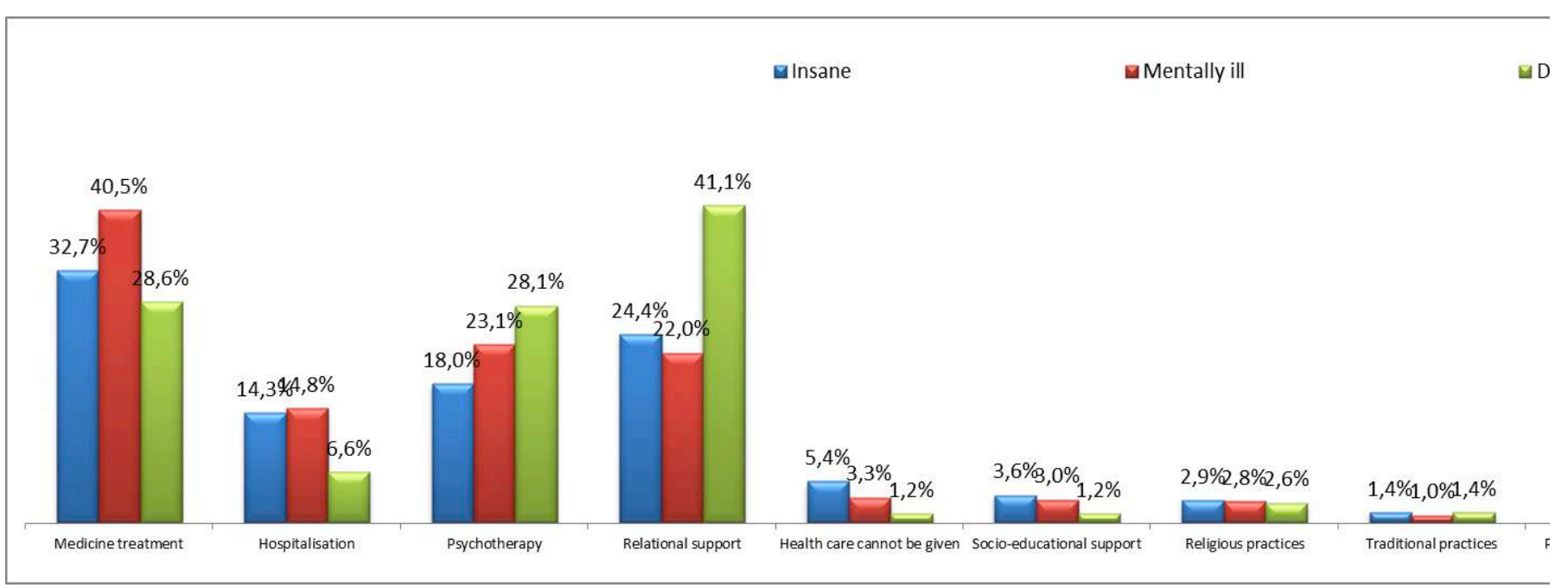




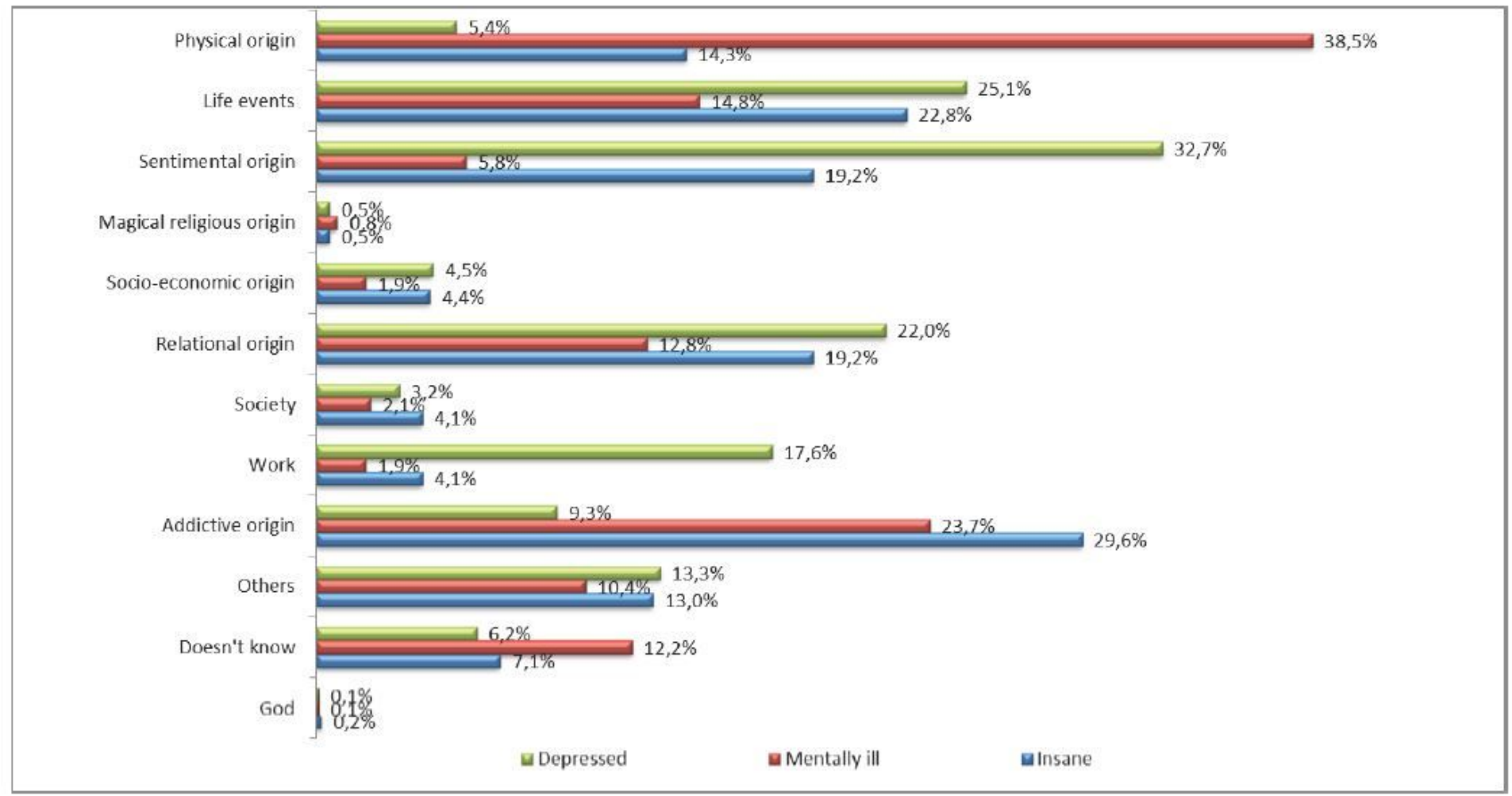

\section{Figure 1}

What do you think can make "insane" / "mentally ill" / "depressed"?

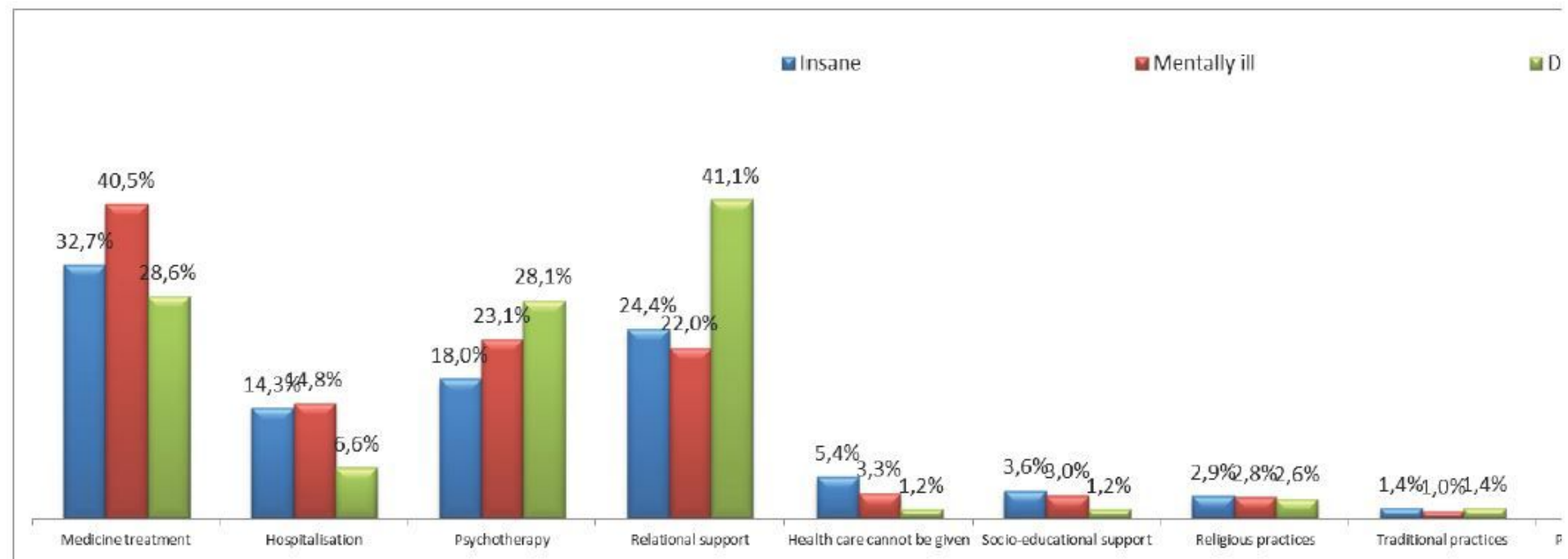

\section{Figure 2}

In your opinion, how can we treat an "insane", a "mentally ill", a "depressed"? 